\title{
First-Quarter Report of Neutron Logging During the Heating Phase of the Drift-Scale Test
}

\author{
W. Lin \\ R. Carlson \\ D. Neubaurer
}

April 1998

This is an informal report intended primarily for internal or limited external distribution. The opinions and conclusions stated are those of the author and may or may not be those of the Laboratory.

Work performed under the auspices of the U.S. Department of Energy by the Lawrence Livermore National Laboratory under Contract W-7405-ENG-48. 


\section{DISCLAIMER}

This document was prepared as an account of work sponsored by an agency of the United States Government. Neither the United States Government nor the University of California nor any of their employees, makes any warranty, express or implied, or assumes any legal liability or responsibility for the accuracy, completeness, or usefulness of any information, apparatus, product, or process disclosed, or represents that its use would not infringe privately owned rights. Reference herein to any specific commercial product, process, or service by trade name, trademark, manufacturer, or otherwise, does not necessarily constitute or imply its endorsement, recommendation, or favoring by the United States Government or the University of California. The views and opinions of authors expressed herein do not necessarily state or reflect those of the United States Government or the University of California, and shall not be used for advertising or product endorsement purposes.

This report has been reproduced directly from the best available copy.

Available to DOE and DOE contractors from the Office of Scientific and Technical Information P.O. Box 62, Oak Ridge, TN 37831

Prices available from (423) 576-8401

Available to the public from the National Technical Information Service

U.S. Department of Commerce 5285 Port Royal Rd. Springfield, VA 22161 


\title{
First-Quarter Report of Neutron Logging During the Heating Phase of the Drift-Scale Test
}

\author{
Milestone SP2640M4 \\ Wunan Lin, Richard Carlson, and Dan Neubaurer
}

\section{Introduction}

The Drift-Scale Test (DST) is one of the thermal tests being conducted in the Exploratory Studies Facility (ESF). One of the purposes of the DST is to study, at the ESF, the coupled thermal-mechanicalhydrologic-chemical (TMHC) processes at the repository horizon of the potential high-level nuclear waste repository at Yucca Mountain, Nevada. The objectives, the test design, and the test layouts of the DST are included in the test design report by the Civilian Radioactive Waste Management System Management and Operation (CRWMS M\&O) contractor $^{[1]}$.

The configuration of the DST includes a declining observation drift driven mostly east and downward from main tunnel in the ESF at approximately $2.827 \mathrm{~km}$ from the north portal. The downward slope of the observation drift (11.5\% to $14.0 \%)$ ensures a minimum of $10 \mathrm{~m}$ of middle nonlithophysal Topopah Spring tuff as the overburden for the DST. The length of the observation drift is approximately $136 \mathrm{~m}$. At the elevation of the DST crown (nominally $10 \mathrm{~m}$ below the upper extent of the middle nonlithophysal Topopah Spring tuff), the connecting drift breaks out to the north from the observation drift $136 \mathrm{~m}$ from the main tunnel of the ESF. The connecting drift extends approximately $40 \mathrm{~m}$ to the north from the observation drift. A heater drift breaks out westward from the connecting drift at approximately $30 \mathrm{~m}$ from the observation drift. The heater drift consists of an 11-m-long entry, which includes a plate-loading niche, and a 47-m-long heated drift. The nominal diameter of the drifts is $5 \mathrm{~m}$. The detail configuration of the DST, including diagrams showing the drift and borehole layout, is included in the test design report by CRWMS M\&O contractor ${ }^{[1]}$.

Thermal neutron logging is a method used to determine moisture content in rocks and soils and will be used to monitor moisture content in boreholes ESF-HD-NEU-1 (N01) to ESF-HD-NEU-10 (N10) (Boreholes \#47 through \#51 and \#64 through \#68), ESF-HD-TEMP-1 (Borehole \#79), and ESF-HD-TEMP-2 (Borehole \#80) in the DST. Boreholes \#79 and \#80 are also identified as neutron holes $\mathrm{N} 11$ and N12, respectively, in this report. 
The neutron probe contains a source of high-energy neutrons and a detector for slow (thermal) neutrons. Water present in rocks slows down the neutrons, making them detectable (because of the presence of hydrogen). Thus, higher counts (or a positive difference in counts relative to background or pre-heat levels) indicate higher water content (or increased water content over background). The probe used in the baseline measurements was a Campbell Pacific Nuclear (CPN) model 503DR. The $3.81-\mathrm{cm}$ - (1.5-in.-) diameter probe was also used for the Single-Heater Test (Serial Number: H37067677).

Under ambient conditions, the sampling volume has a diameter approximately $15 \mathrm{~cm}$ surrounding the probe, which increases as moisture content decreases. Measurements are sensitive to the presence of elements, such as chlorine and boron, that have large neutron-capture cross-sections. By considering the counting statistics and other uncertainties, such as location of the tool, the uncertainty of the neutron logging is approximately $3 \%$ to $5 \%$ in water content. A new neutron tool made by COMPROBE, Inc., (Model COMPROBE 1805DF) has been purchased for measuring the neutron counts of the rock mass during the heating and cooling phases of the DST. The COMPROBE tool is designed for operating at temperatures to $200^{\circ} \mathrm{C}$. The COMPROBE probe was used to take the measurements during the heating phase; these measurements, along with the baseline data, are presented in this report.

The COMPROBE probe has not yet been calibrated. However, when the COMPROBE probe was first used in the logging, its neutron counts were compared with those of the CPN probe placed at the same location in a hole. The neutron counts of the COMPROBE probe were then normalized to those of the CPN probe. The CPN probe was calibrated to the Teflon liner/grout assembly of the Single-Heater Test (SHT), but has not yet been calibrated to the Teflon/grout assembly of the DST. The Teflon/grout assembly in the DST is very similar, but not identical, to that in the SHT. The calibration coefficients of the CPN probe were then used to reduce the baseline neutron counts, which were measured by the CPN probe, to calculate the baseline fraction volume water contents. The calibration coefficients of the CPN probe were then used to reduce the normalized neutron counts of the COMPROBE probe to calculate fraction volume water content measured by the COMPROBE probe. This process of reducing the COMPROBE data provides timely information about the water content in the DST during the heating phase. The calculated fraction volume water content reported in this report should be considered as preliminary and nonqualified (non-Q). When both the CPN probe and the COMPROBE probe are 
calibrated in the exact borehole assembly used in the DST, the neutron data will be re-analyzed, and the fraction volume water content will be recalculated.

For boreholes ESF-HD-NEU-1 through ESF-HD-NEU-10 of the DST, a Teflon tube was inserted into the boreholes and grouted into place. The Teflon tube permits easy insertion, placement, and removal of the tool. The CPN probe had been calibrated in the similar Teflon-grout assembly, which was used in the SHT but which is not identical to that used in the holes. Calibration of the COMPROBE probe recalibration of the CPN prove will be conducted. For boreholes ESF-HD-TEMP-1 (Borehole \#79) and ESFHD-TEMP-2 (Borehole \#80), one resistance-temperature device (RTD) bundle was attached to the outside of the Teflon liner, and the assembly was grouted in place in the holes. The CPN probe had been calibrated in the Teflon-RTD-grout assembly used in the SHT and will be calibrated to a borehole assembly identical to that used in the Boreholes \#79 and \#80. Calibrations of the COMPROBE probe in the same assembly will also be conducted. The calibration information will be used to convert the neutron counts reported in this document into fraction volume water content.

\section{Measurement Procedures}

The following procedure describes the method of collecting the baseline neutron data of the DST. The COMPROBE continuously measures neutron counts, with a continuous, $2-\mathrm{sec}$ smoothing of the counts. Standard counts, which are neutron counts when the tool is in its holder thus minimizing the influence of the rock mass to be measured, were measured and recorded immediately prior to, and subsequent to, performing measurements. The neutron probe was placed in a borehole at a specific location (depth), and the neutron count was hand-recorded in a scientific notebook; it was also recorded electronically in the device's memory. Upon completion of the test, data was downloaded to a computer, and the data values were checked against the hand-recorded values. Data were recorded at depth intervals of $10 \mathrm{~cm}$ in each borehole. The procedures are described in TIP-NF-3 $1^{[2]}$.

In all of the holes, at least two measurements were conducted during the heating phase: one in February 1998, and one in March 1998. Originally, it was planned to start the in-heat measurement in the time window of December 1997 and January 1998. However, due to scheduling difficulty, only partial measurements were conducted in mid-December 1997 to detect any change of the moisture at the beginning of the heating phase. The partial measurements involved logging in some of the holes at depths near the heaters. Not much change in the moisture content was 
detected. A decision was made to start full-scale logging in February 1998 instead of in January 1998. The results of those measurements in mid-December 1997 are shown in Figures 15, 16, 20, and 21. In Borehole \#50 (N04), the measurement on February 6, 1998, was repeated once to check for repeatability, as was the measurement in Borehole \#67 (N09) on March 18, 1998.

\section{The Baseline Fraction Volume Water Contents}

As reported in Level 4 Milestone SPY195M4 ${ }^{[3]}$, the baseline neutron logging was conducted in September, October, and November 1997. The baseline fraction volume water contents in the 12 boreholes in the DST are shown in Figures 1 through 12, for Boreholes ESF-HD-NEU-1 (N01) through ESF-HD-NEU-10 (N10) and ESF-HD-TEMP-1 (N11) through ESF-HDTEMP-2 (N12), respectively. Each one of these figures presents the two baseline neutron logs in the hole. In all of these holes, the baseline neutron logging was conducted after the Teflon liner had been grouted in place. Therefore, the baseline fraction volume water content in these holes is influenced by the water content in the grout. The grout had been cured prior to the baseline logging so that the water content in the grout was not expected to change during the test. In addition to showing the baseline neutron logs in Hole ESF-HD-TEMP-2 (N12), Figure 12 shows the neutron logs in this hole before it was grouted.

Except for some localized spikes, which may be related to fractures, the baseline fraction volume water contents in the neutron holes N01 through N10 range from 0.07 to 0.15 . As shown in Figure 1, there seems to be no grout in the deeper $12 \mathrm{~m}$ of Borehole \#47 (N01), and the baseline fraction volume water in there is only about 0.05 . Figure 12 shows a similar situation in Borehole \#80 (N12). The baseline fraction volume water contents in Boreholes \#79 (N11) and \#80 (N12) are greater than those in the other holes and range from 0.12 to 0.2 . This may be at least partially due to the fact that the borehole diameter of \#79 and \#80 is $10.16 \mathrm{~cm}$, and the nominal diameter of the other holes is $7.62 \mathrm{~cm}$; therefore, the grout columns in $\mathrm{N} 11$ and $\mathrm{N} 12$ are thicker than those in the other holes. The relatively low fraction volume water content at the collar of most of those holes may be influenced by the environment outside the hole. These holes will be closely watched during the logging in the heating phase of the DST. 


\section{The Heating Phase Neutron Data and Discussion}

The difference fraction volume water contents in the 12 neutron holes are presented in this report. The difference fraction volume water is calculated by subtracting the mean baseline fraction volume water (as shown in Figures 1-12) from that measured during the heating phase. Figures 13-24 show the difference fraction volume water content in the 12 boreholes (N01 through N12, respectively). Each one of these figures presents all the heating phase data obtained in the hole to date.

The difference fraction volume water contents in Boreholes \#47 (N01) through \#51 (N05) are shown in Figures 13 to 17. These holes form a fan-shaped cross section that extends from the access/observation drift (AOD) to the heater drift (HD) at about $6.4 \mathrm{~m}$ from the bulkhead of the heater drift $^{[1]}$. In general, the water content did not change much in these holes, except for the appearance of some spikes of both increasing (positive) and decreasing (negative) moisture content. The spikes are localized phenomena. They may be related to the effect of fractures or other localized variations in water content. Figure 16 shows that the two measurements in Borehole \#50 repeated quite well on February 6, 1998.

Figures 18-22 show the difference fraction volume water contents in Boreholes \#64 (N06) through \#68 (N10), respectively. These holes form a fan-shaped cross section that extends from the AOD to the HD at about $26.5 \mathrm{~m}$ from the bulkhead of the $\mathrm{HD}^{[1]}$. Generally, there was not much change in the moisture content, except for the appearance of some local variations, similar to those mentioned in preceding paragraph. Figure 21 shows that a drying region has been developing in Borehole \#67 at about $18 \mathrm{~m}$ from the collar. Among this the five holes in this group, this hole is located at a shortest distance from the wing heaters. The apparent drying in this part of the rock mass is consistent with the temperature data ${ }^{[4]}$. However, Borehole \#50 is located at about the same distance from the wing heaters, at a different location of course, but no drying is indicated (Figure 4). These phenomena will be watched closely during the heating phase. Figure 21 also shows that the two measurements in Borehole \#67 on March 18, 1998, repeated well.

Figures 23 and 24 show the difference fraction volume water contents in Boreholes \#79 and \#80, respectively. These two holes are parallel to the axis of the HD and about $3.5 \mathrm{~m}$ above the wing heaters. These figures show a slight, and fairly uniform, decrease in moisture content in these two holes. Figure 24 shows that the moisture content in the deeper $15-\mathrm{m}$ section of Borehole \#80 increased relative to the outer portion of this hole. As indicated in the baseline neutron logging ${ }^{[3]}$, the 
deeper portion of this hole is probably not grouted. At least part of the cause for the apparent increase in moisture content is the low baseline water content of an empty hole, as shown in Figure 12. Other explanations of this apparent increase in the water content will be further investigated.

\section{Summary}

All of the baseline neutron data have been converted into fraction volume water content. Neutron measurements have been conducted during the heating phase of the DST. Preliminary data indicate that, in about four months of heating, drying has occurred at certain locations near the wing heaters. Further analyses of the neutron data will be conducted

\section{Future Plans}

The DST continues in the heating phase. The neutron logging will be continued using the COMPROBE tool. Calibrations of both the COMPROBE tool and the CPN tool in the exact Teflon-grout and Teflon-grout-RTD assemblies, as used in the DST, will be conducted. Then the baseline neutron counts and the future neutron counts during the heating phase will be converted into fraction volume water contents. The neutron logging will continue approximately once per month.

\section{Acknowledgments}

This work was supported by the Yucca Mountain Site characterization Project and was performed under the auspices of the U.S. Department of Energy by the Lawrence Livermore National Laboratory under Contract W-7405-Eng-48. 


\section{References}

[1] Civilian Radioactive Waste Management System Management and Operation Contractor (OCRWM M\&O). 1996. "Test Design, Plans, and Layout for the First ESF Thermal Test." Rev. 1, BAB000000-017174600-00025. Las Vegas, NV: TRW Environmental Safety System, Inc..

[2] Lawrence Livermore National Laboratory Yucca Mountain Project Technical Implementation Plan. 1994. Neutron and Gamma (Density) Logging in Welded Tuff. TIP-NF-31, Rev. 1. Livermore, CA: Lawrence Livermore National Laboratory.

[3] Lin, W., R. Carlson, and D. Neubaurer. 1998. "Baseline Neutron Logging Measurements in the Drift-Scale Test." Milestone \#SPY195M4. Livermore, CA: Lawrence Livermore National Laboratory.

[4] Blair, S. 1998. "Temperature Measurements in the Drift-Scale Test." Milestone \#SP2640M4. Livermore, CA: Lawrence Livermore National Laboratory. 
Baseline fraction volume water content in Hole \#47 of the DST.

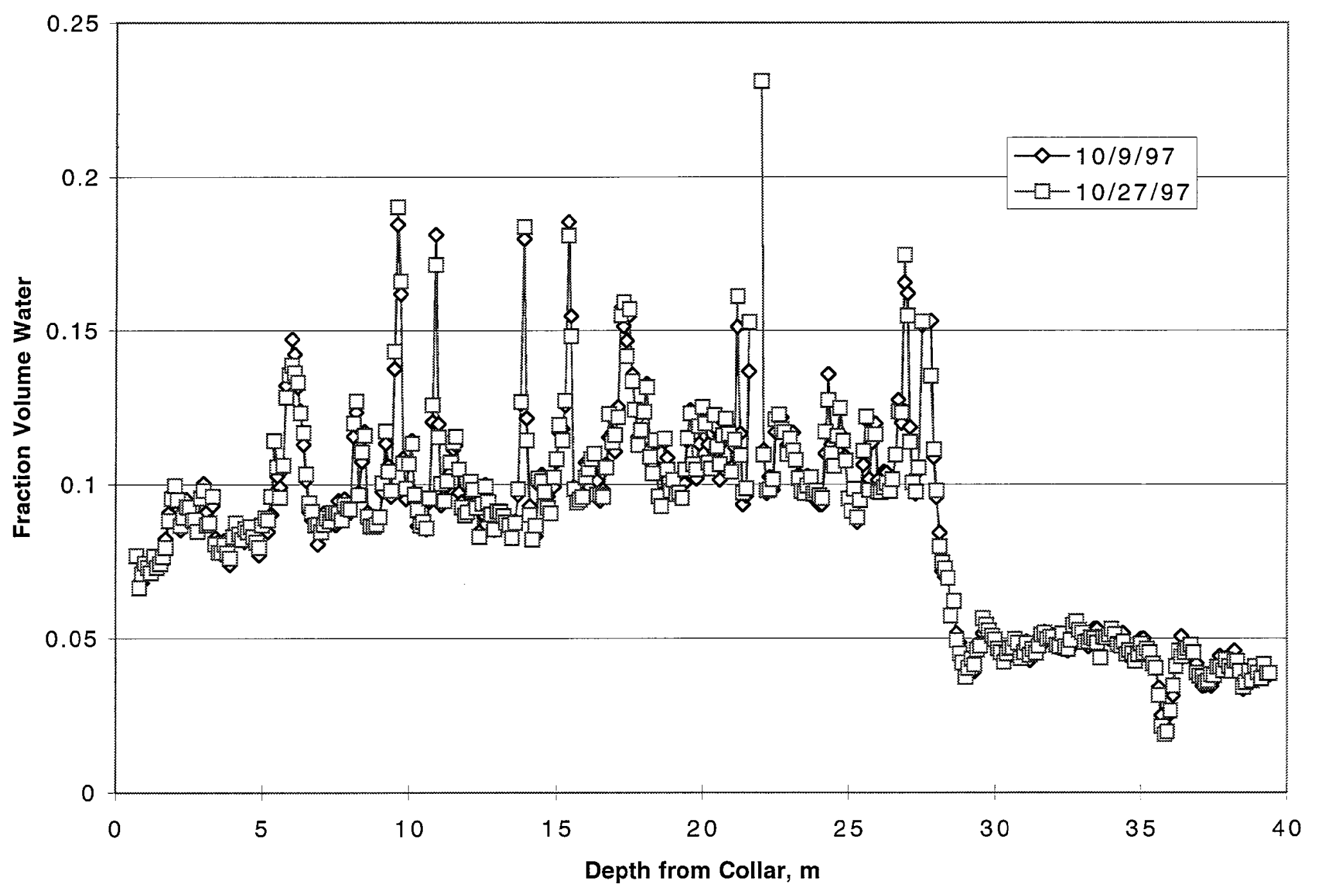

Figure 1. Baesline fraction volume water content in Hole \#47 (N01). 
Baseline fraction volume water content in Hole \#48 of the DST.

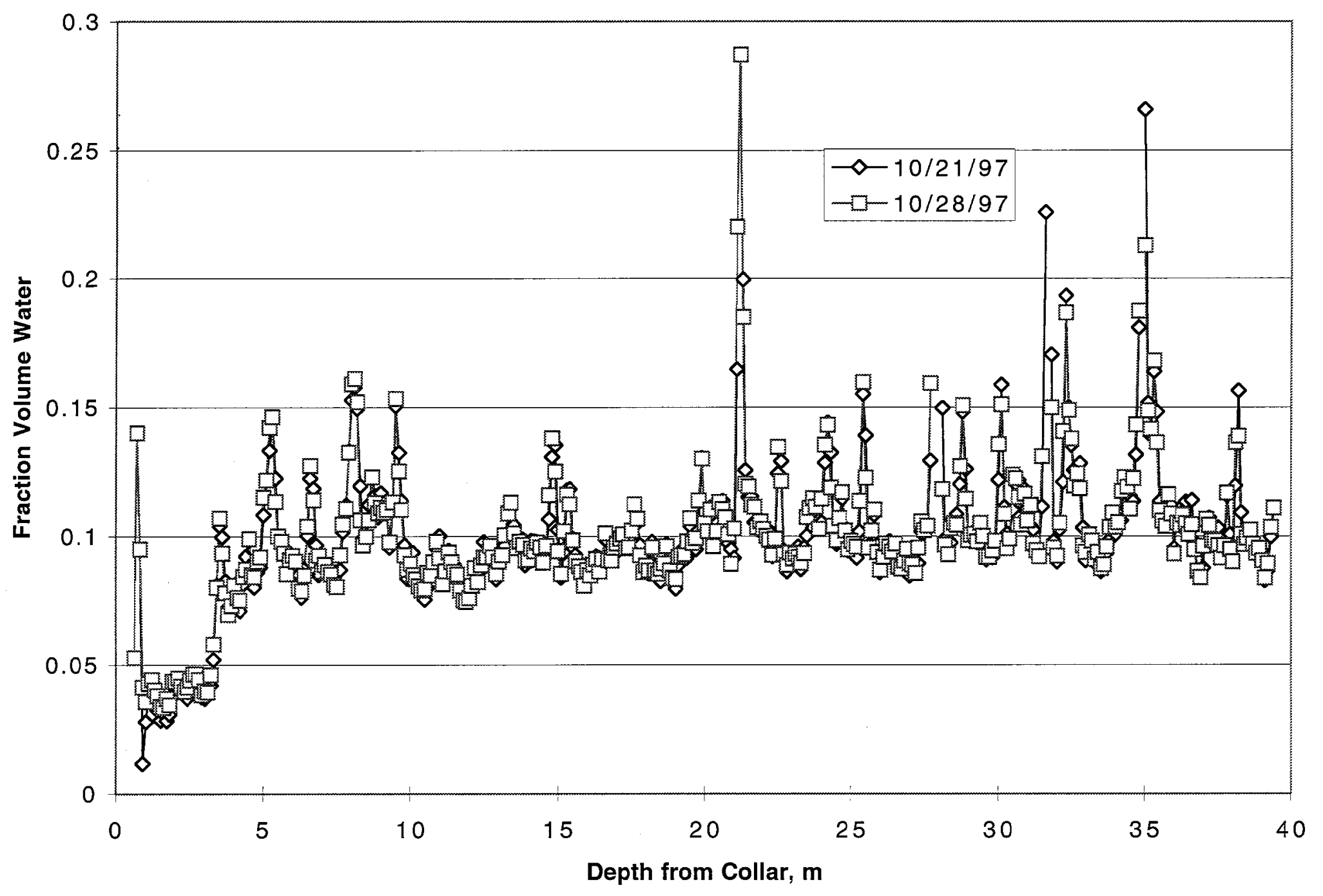

Figure 2. Baseline fraction volume water content in Hole \#48 (N02). 
Baseline fraction volume water content in Hole \#49 of the DST.

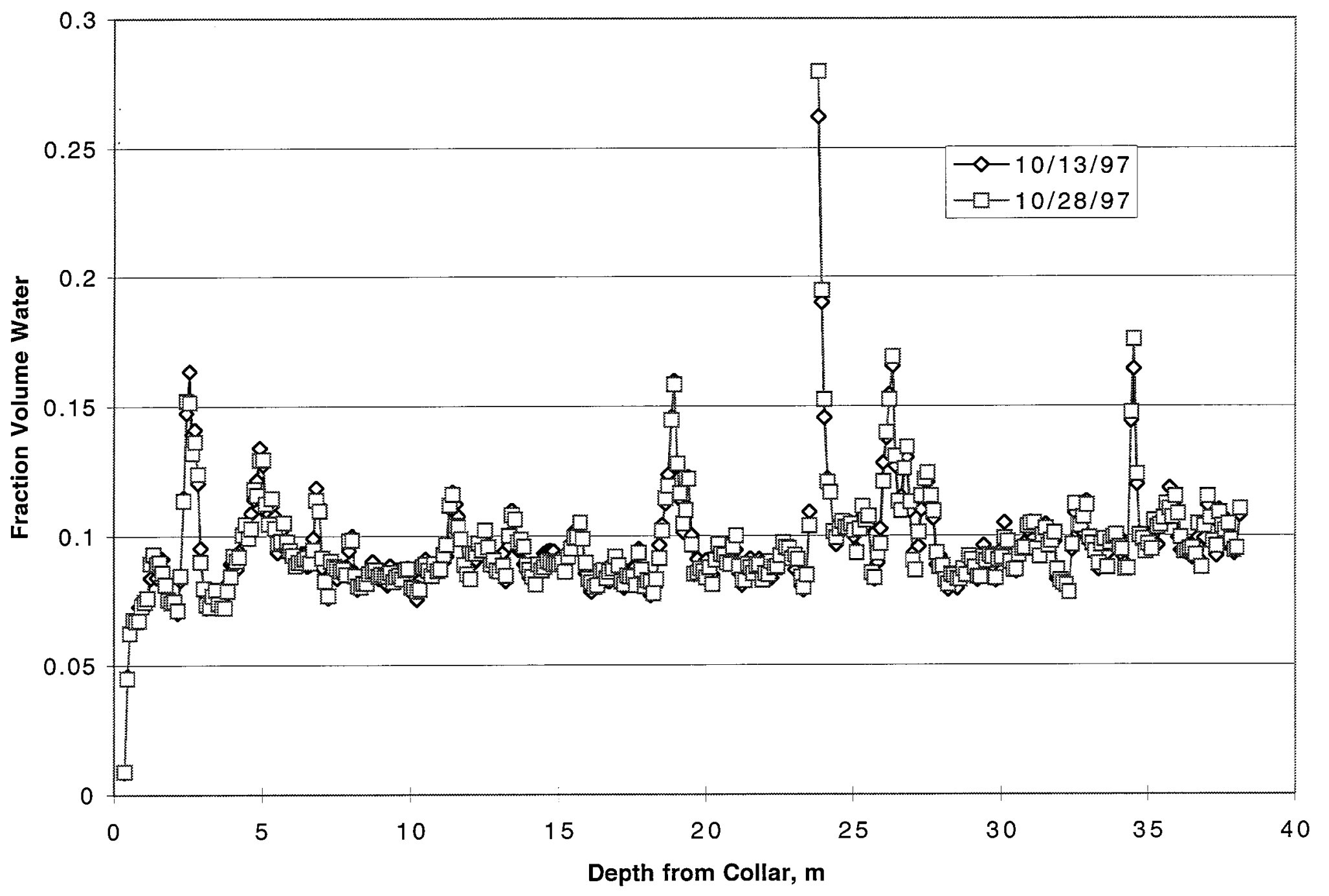

Figure 3. Baseline fraction volume water content in Hole \#49 (N03). 
Baseline fraction volume water content in Hole \#50 of the DST.

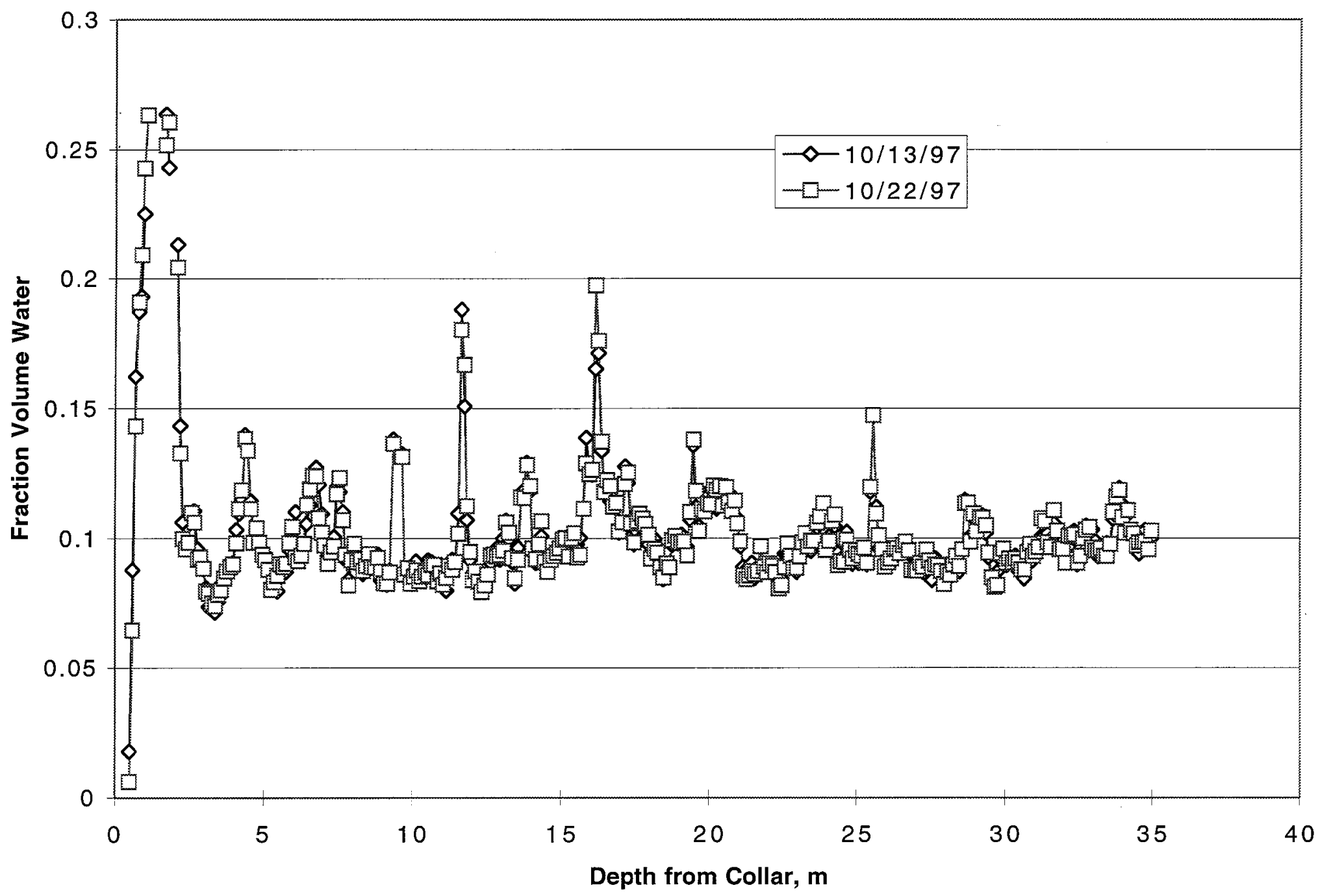

Figure 4. Baseline fraction volume water content in Hole \#50 (N04). 
Baseline fraction volume water content in Hole \#51 of the DST.

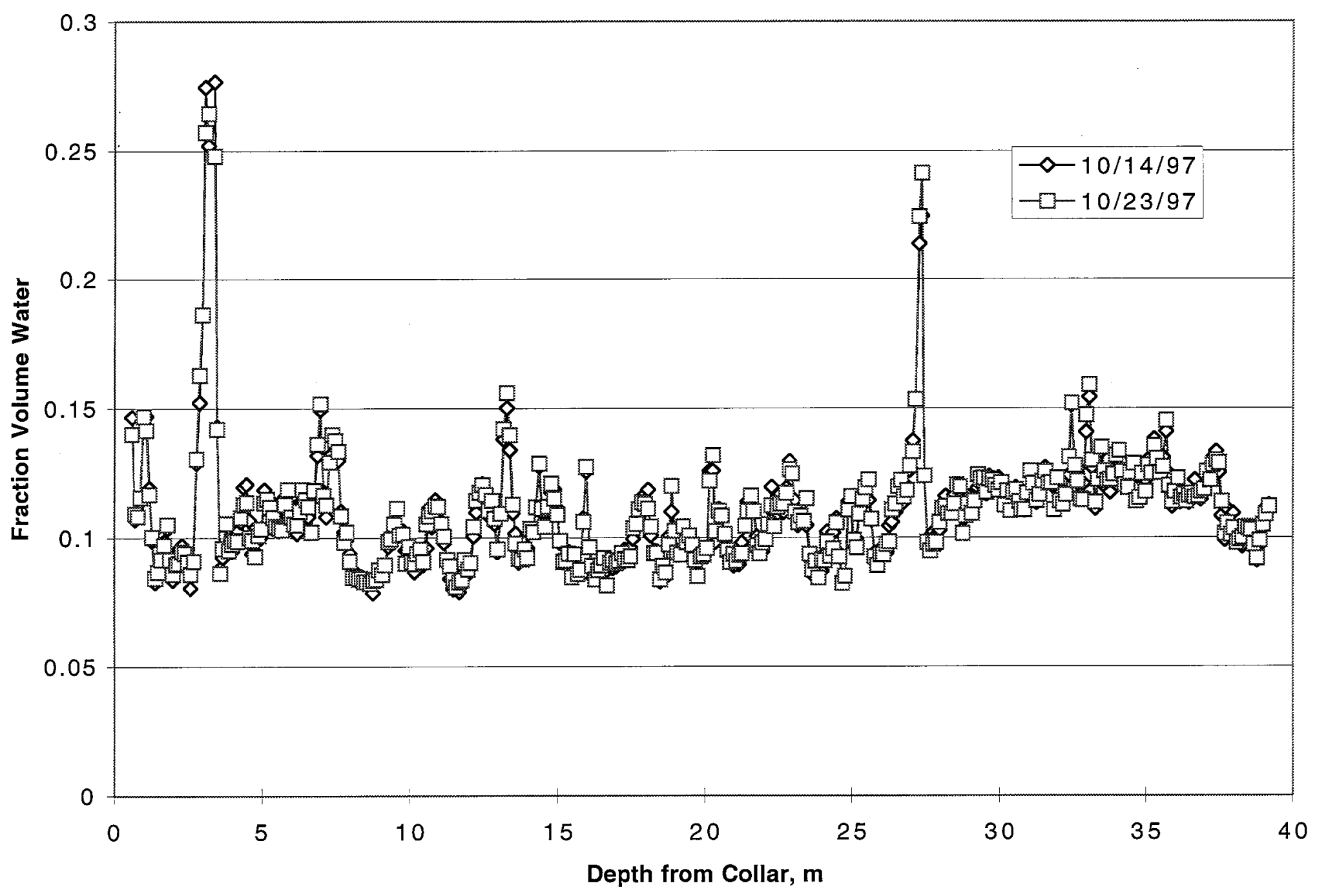

Figure 5. Baseline fraction volume water content in Hole \#51 (N05). 
Baseline fraction volume water content in Hole \#64 of the DST.

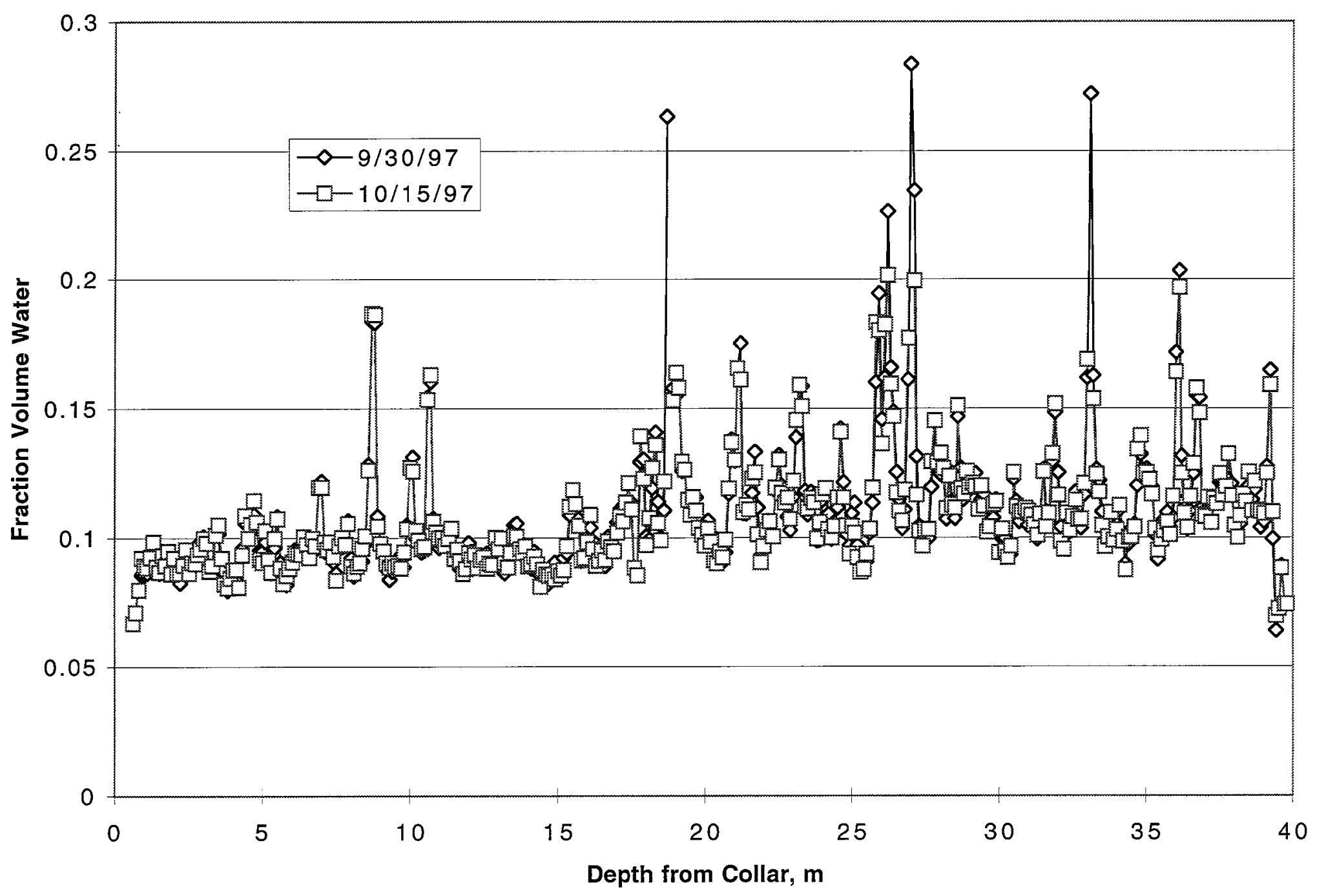

Figure 6. Baseline fraction volume water content in Hole \#64 (N06). 
Baseline fraction volume water content in Hole \#65 of the DST.

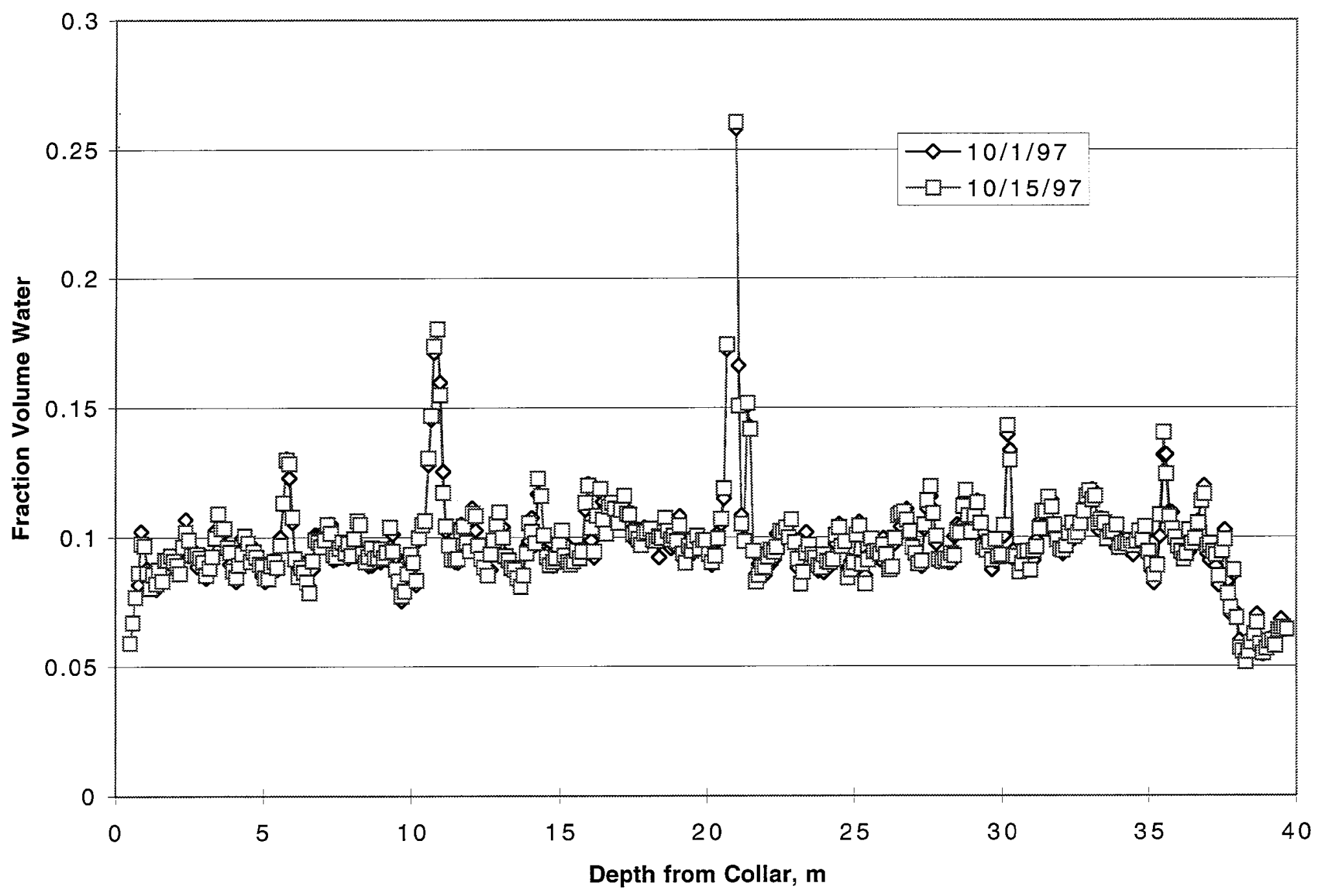

Figure 7. Baseline fraction volume water content in Hole \#65 (N07). 
Baseline fraction volume water content in Hole \#66 of the DST.

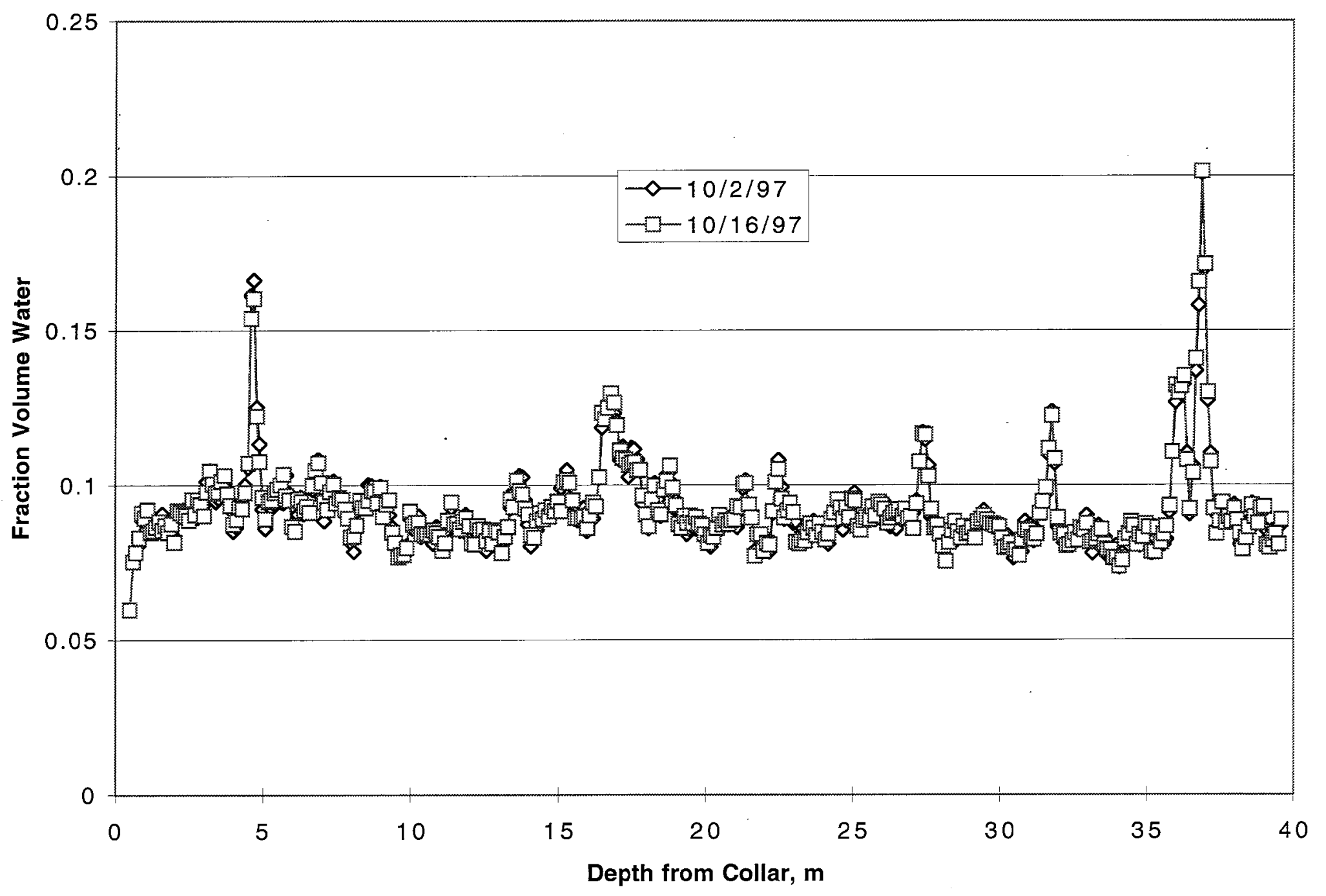

Figure 8. Baseline fraction volume water content in Hole \#66 (N08). 
Baseline fraction volume water content in Hole \#67 of the DST.

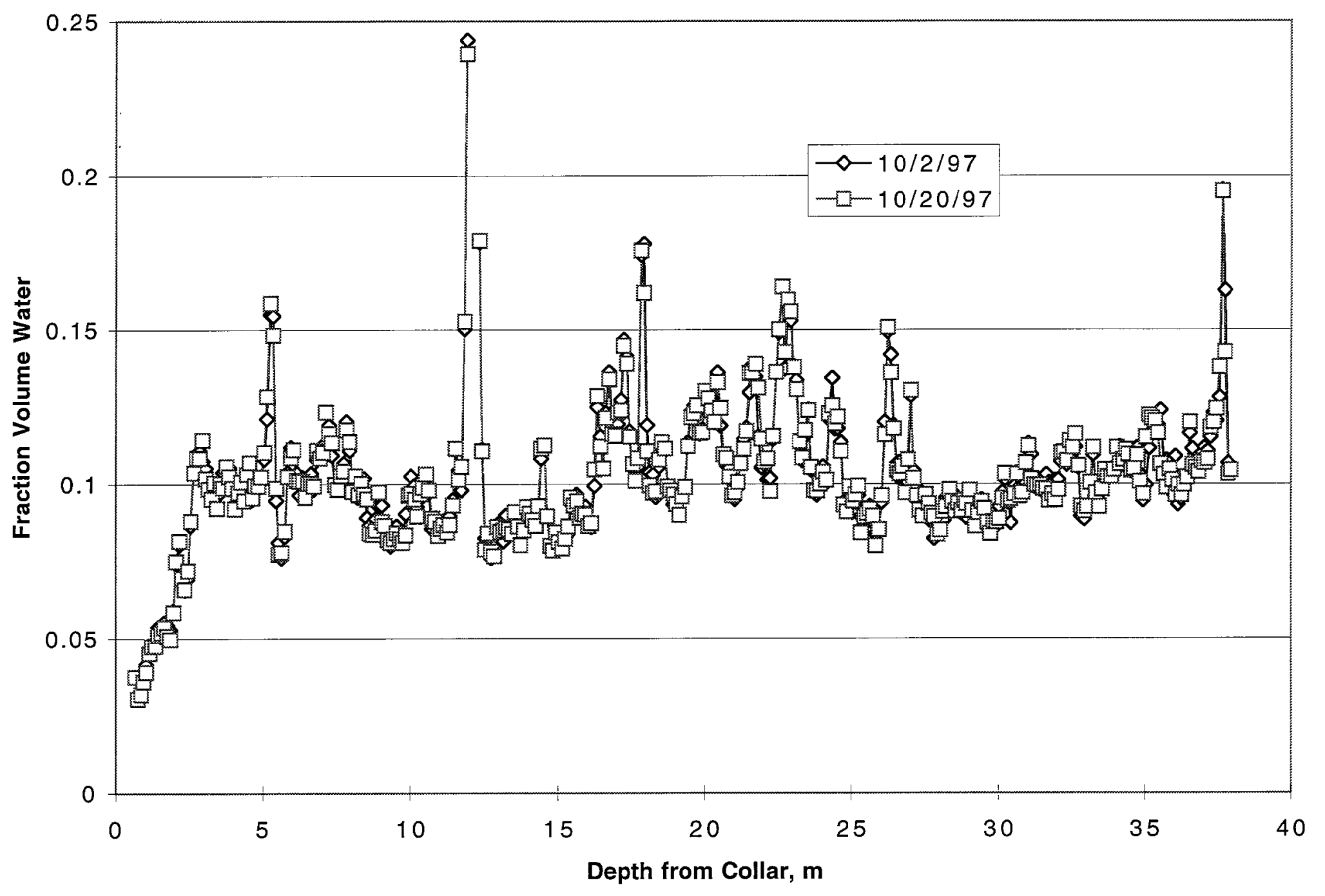

Figure 9. Baseline fraction volume water content in Hole \#67 (N09). 
Baseline fraction volume water content in Hole \#68 of the DST.

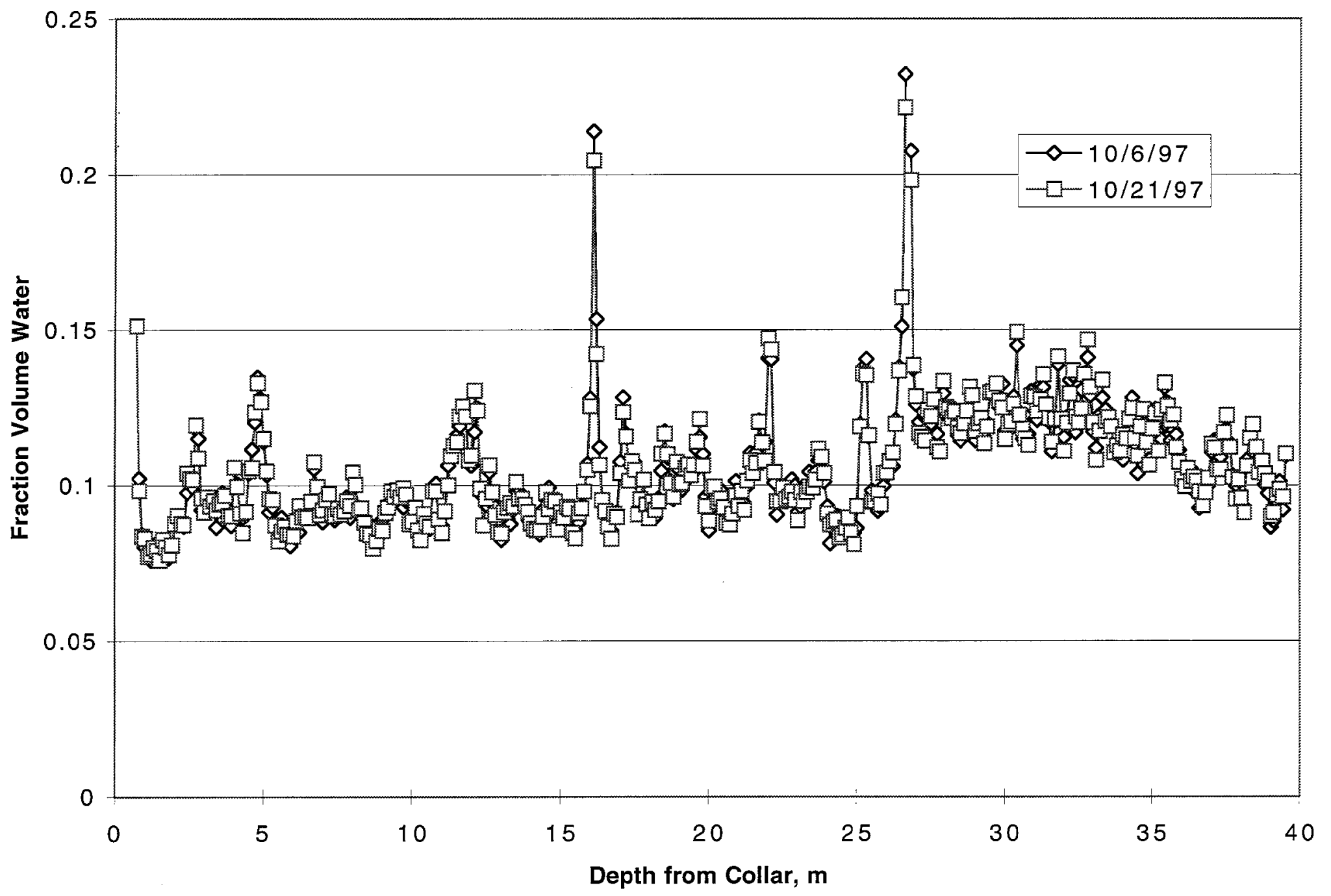

Figure 10. Baseline fraction volume water content in Hole \#68 (N10). 
Baseline fraction volume water content in Hole \#79 of the DST.

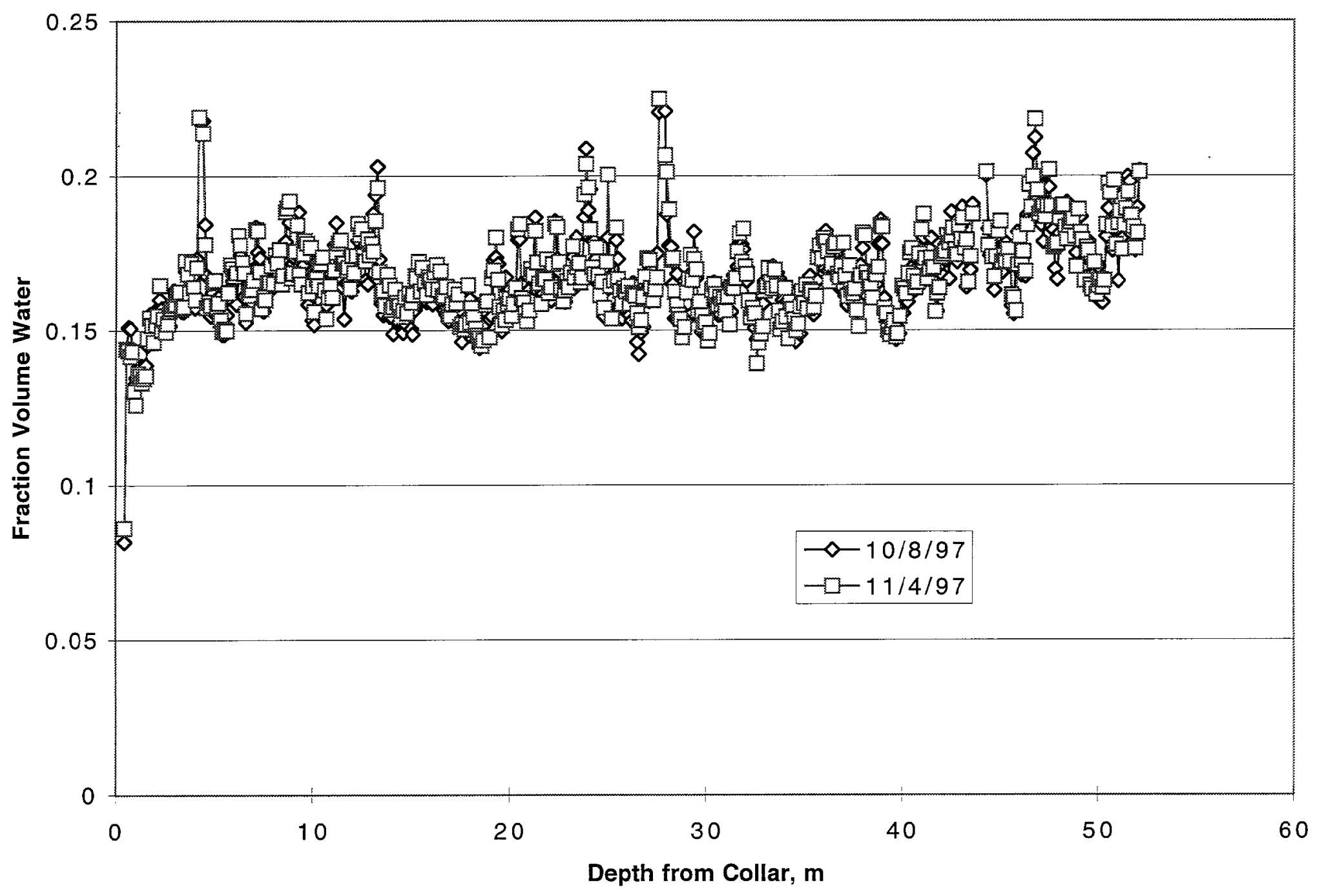

Figure 11. Baseline fraction volume water content in Hole \#79 (N11). 
Baseline fraction volume water content in Hole \#80 of the DST.

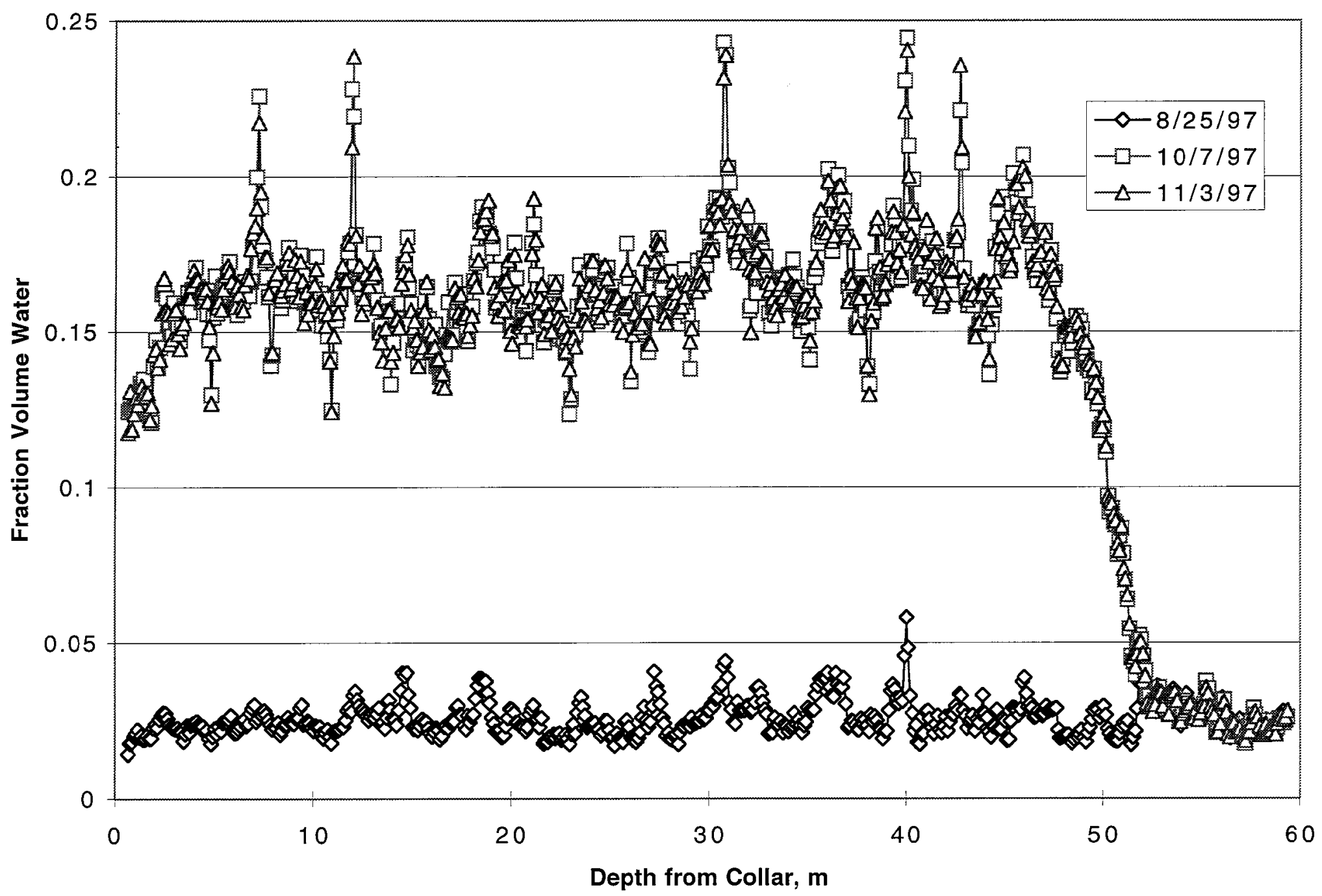

Figure 12. Baseline fraction volume water content in Hole \#80 (N12). 
Difference fraction volume water content in Hole \#47 of the DST.

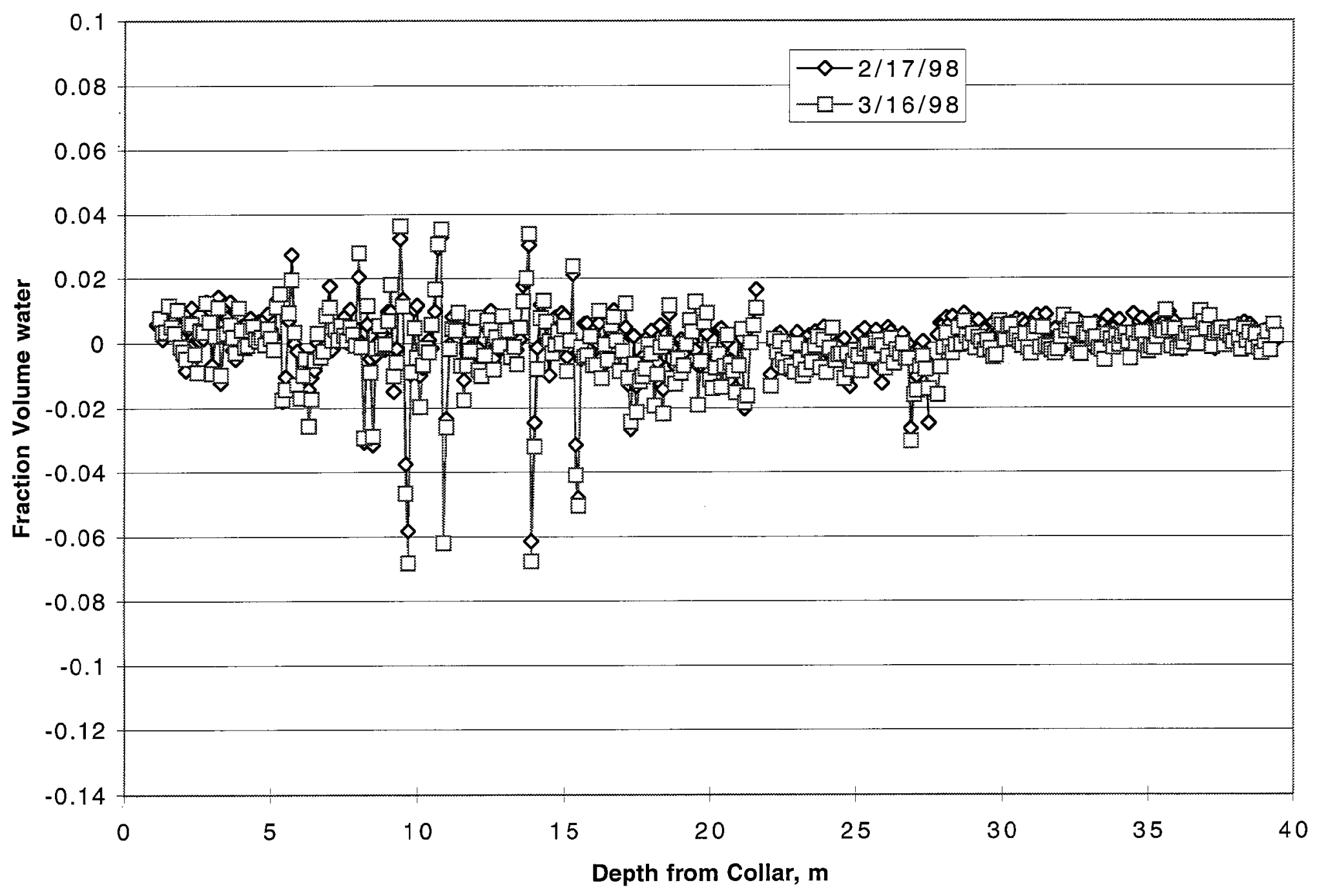

Figure 13. Difference fraction volume water content in Hole \#47 (N01). 
Difference fraction volume water content in Hole \#48 of the DST.

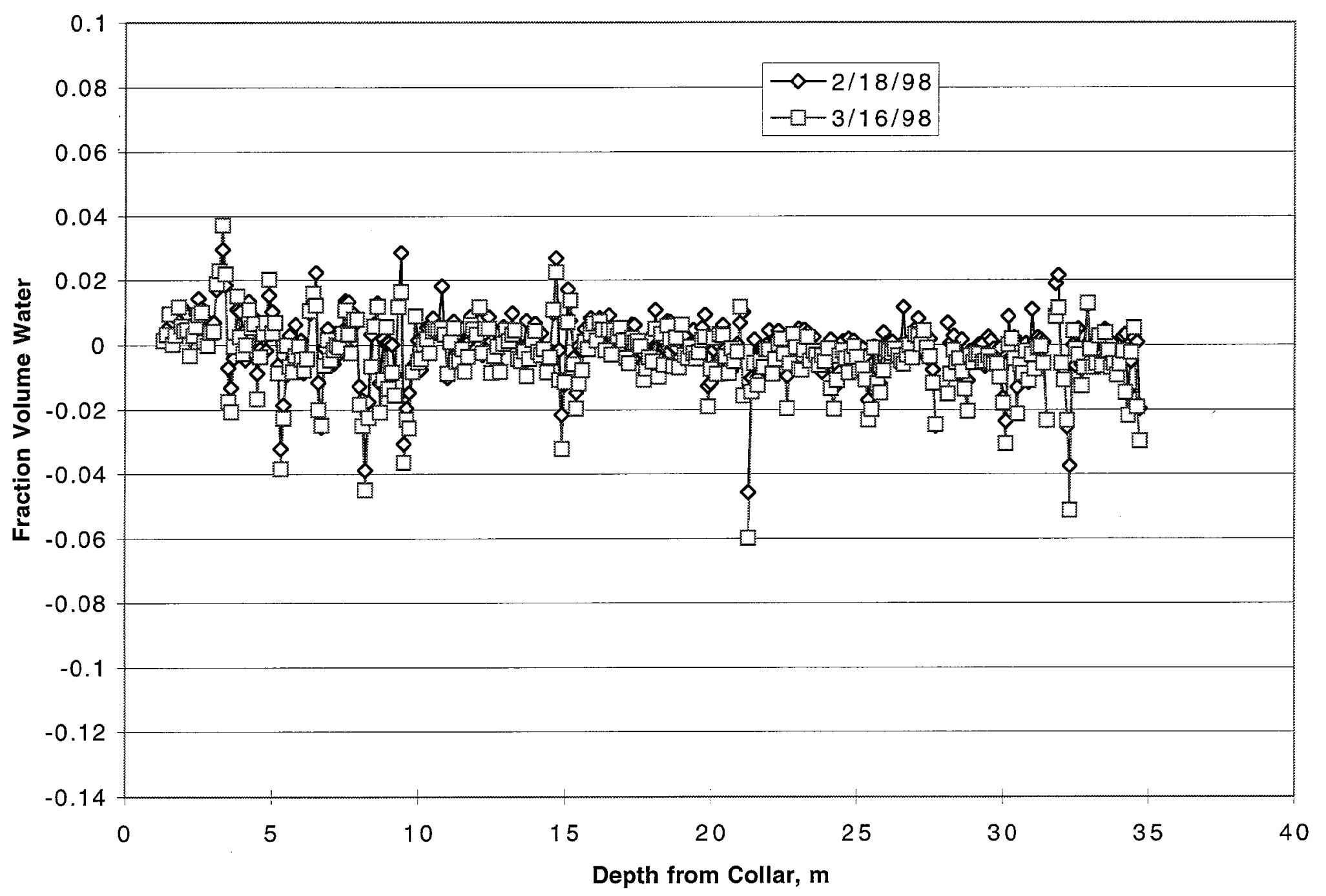

Figure 14. Difference fraction volume water content in Hole \#48 (N02). 
Difference fraction volume water content in Hole \#49 of the DST.

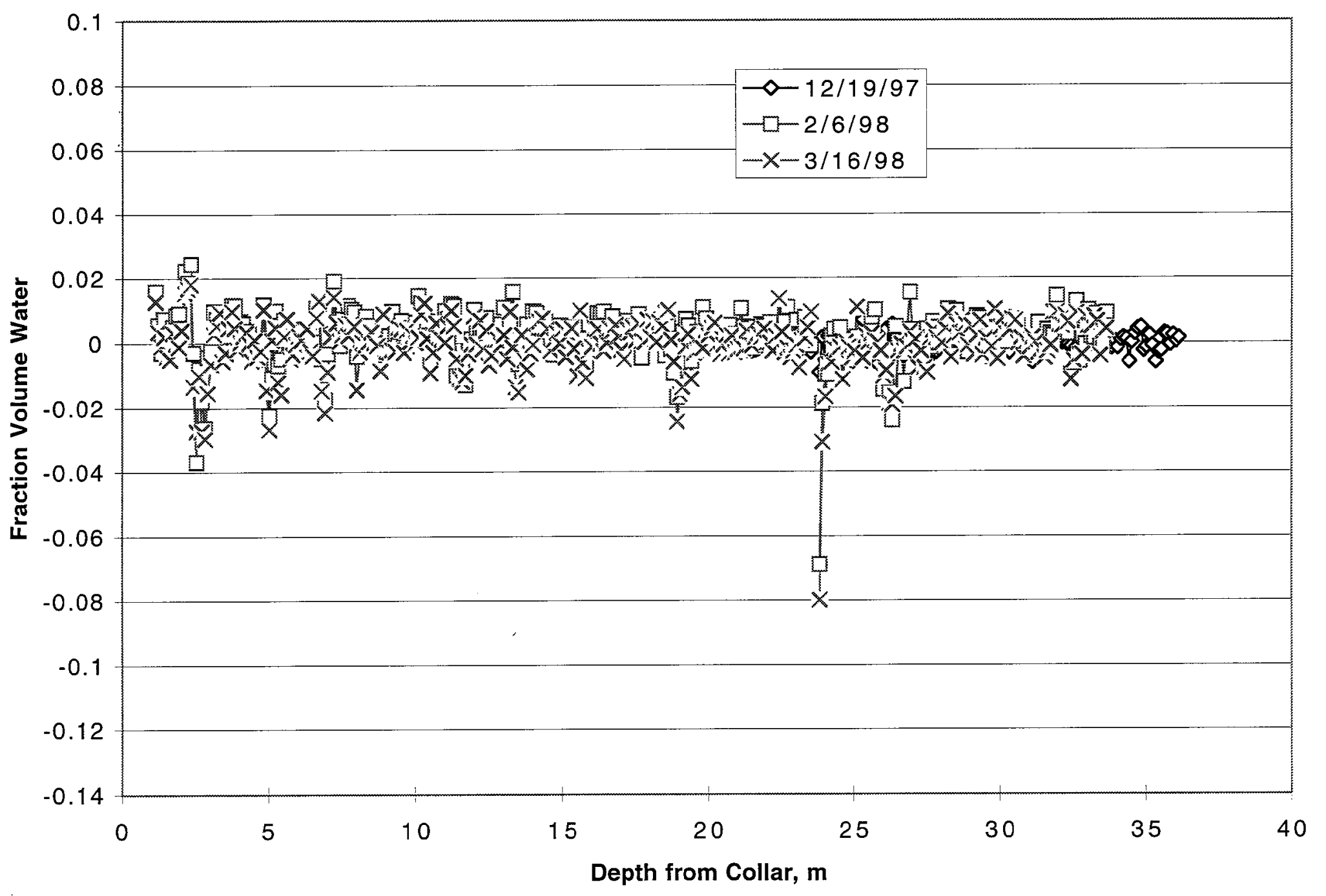

Figure 15. Difference fraction volume water content in Hole \#49 (N03). 
Difference fraction volume water content in Hole \#50 of the DST.

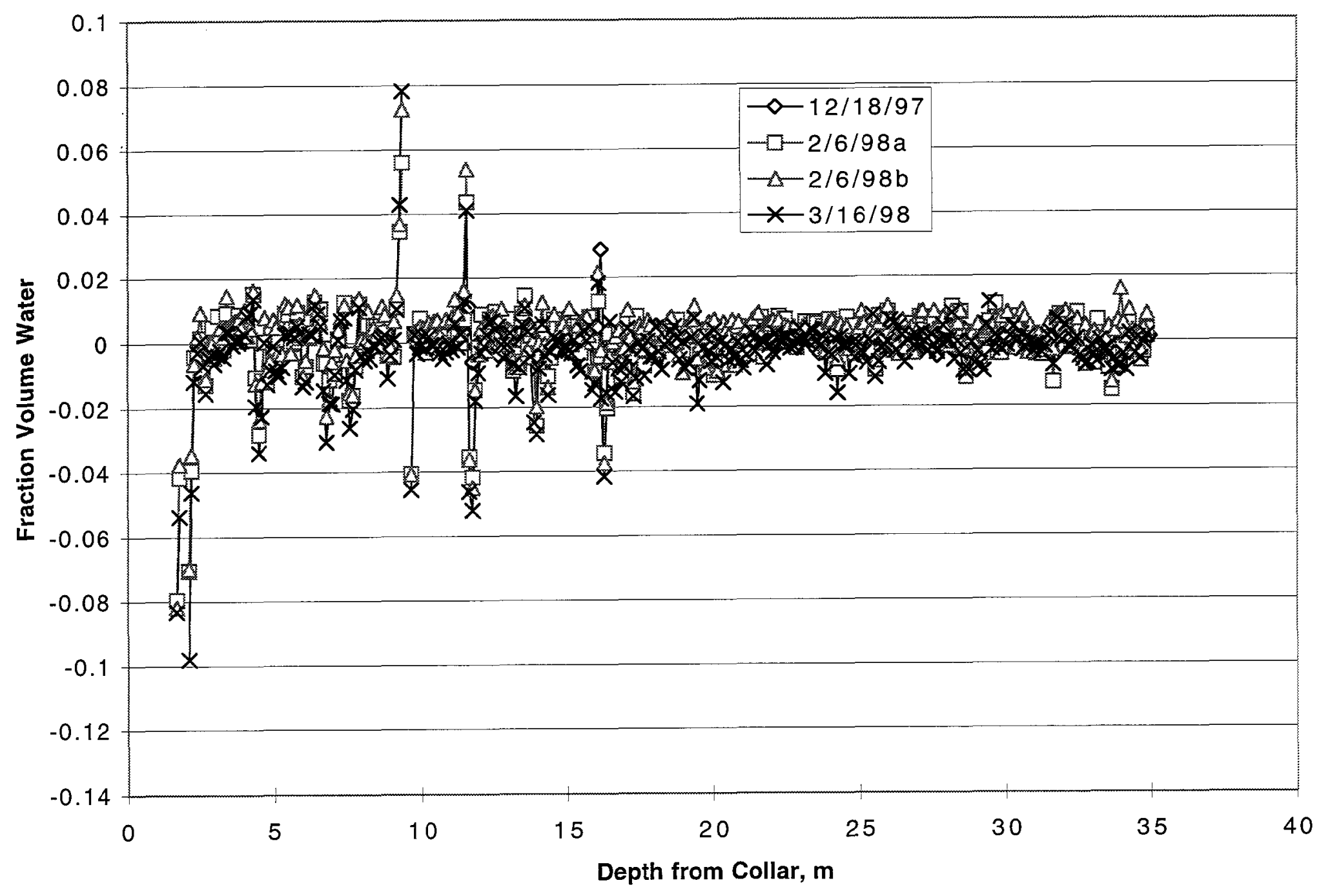

Figure 16. Difference fraction volume water content in Hole \#50 (N04). 
Difference fraction volume water content in Hole \#51 of the DST.

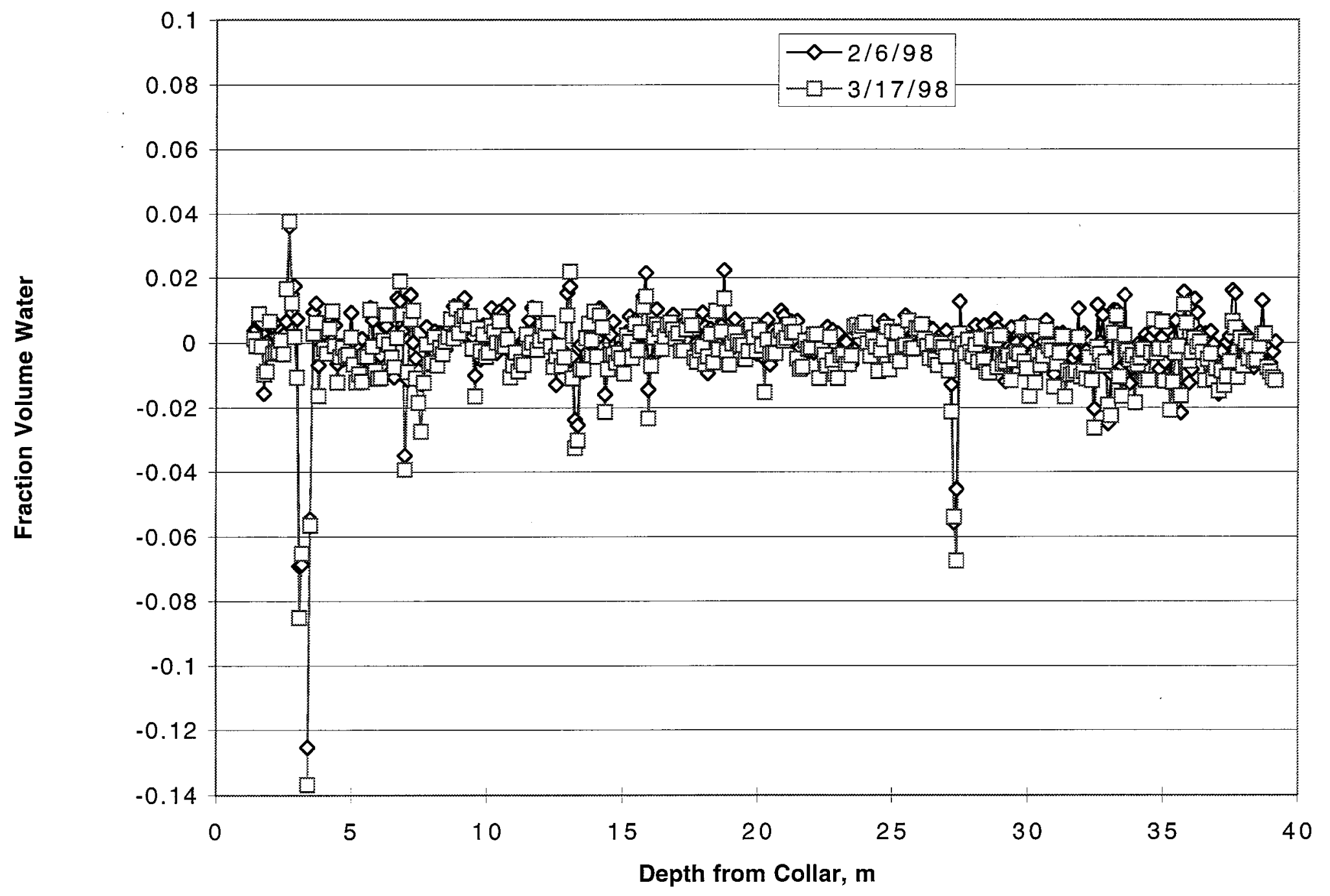

Figure 17. Difference fraction volume water content in Hole \#51 (N05). 
Difference fraction volume water content in Hole \#64 of the DST.

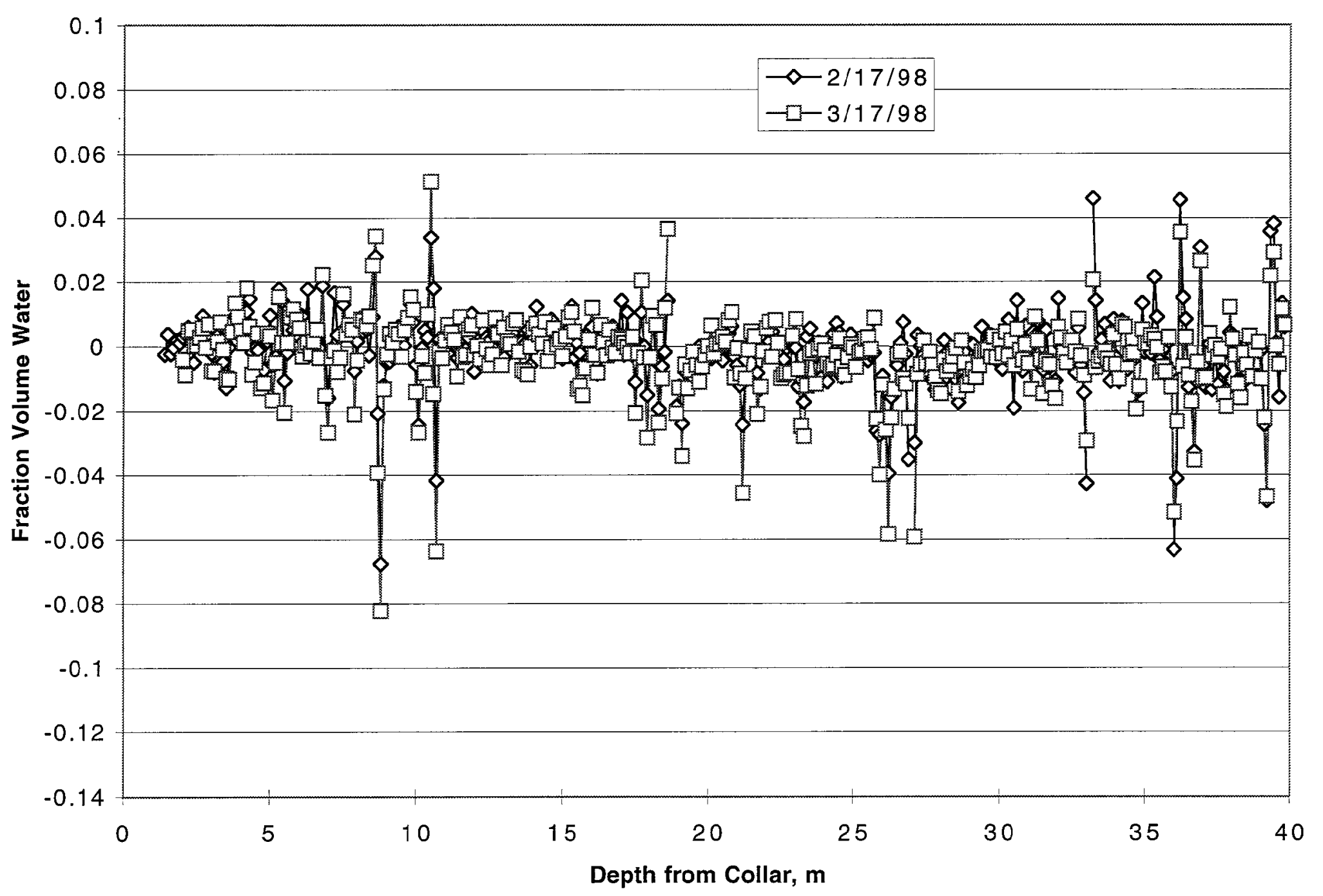

Figure 18. Difference fraction volume water content in Hole \#64 (N06). 
Difference fraction volume water content in Hole \#65 of the DST.

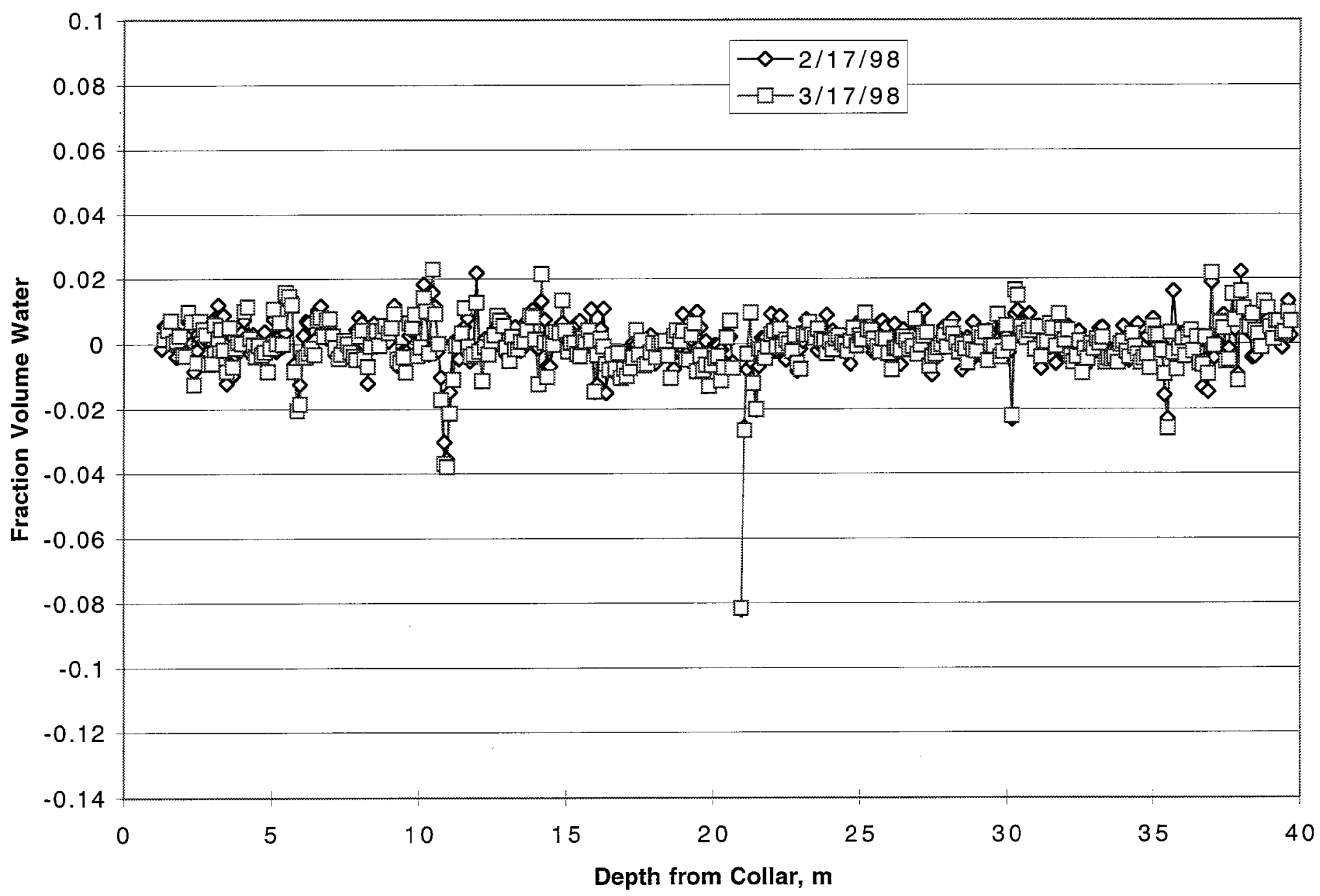

Figure 19. Difference fraction volume water content in Hole \#65 (N07). 
Difference fraction volume water content in Hole \#66 of the DST.

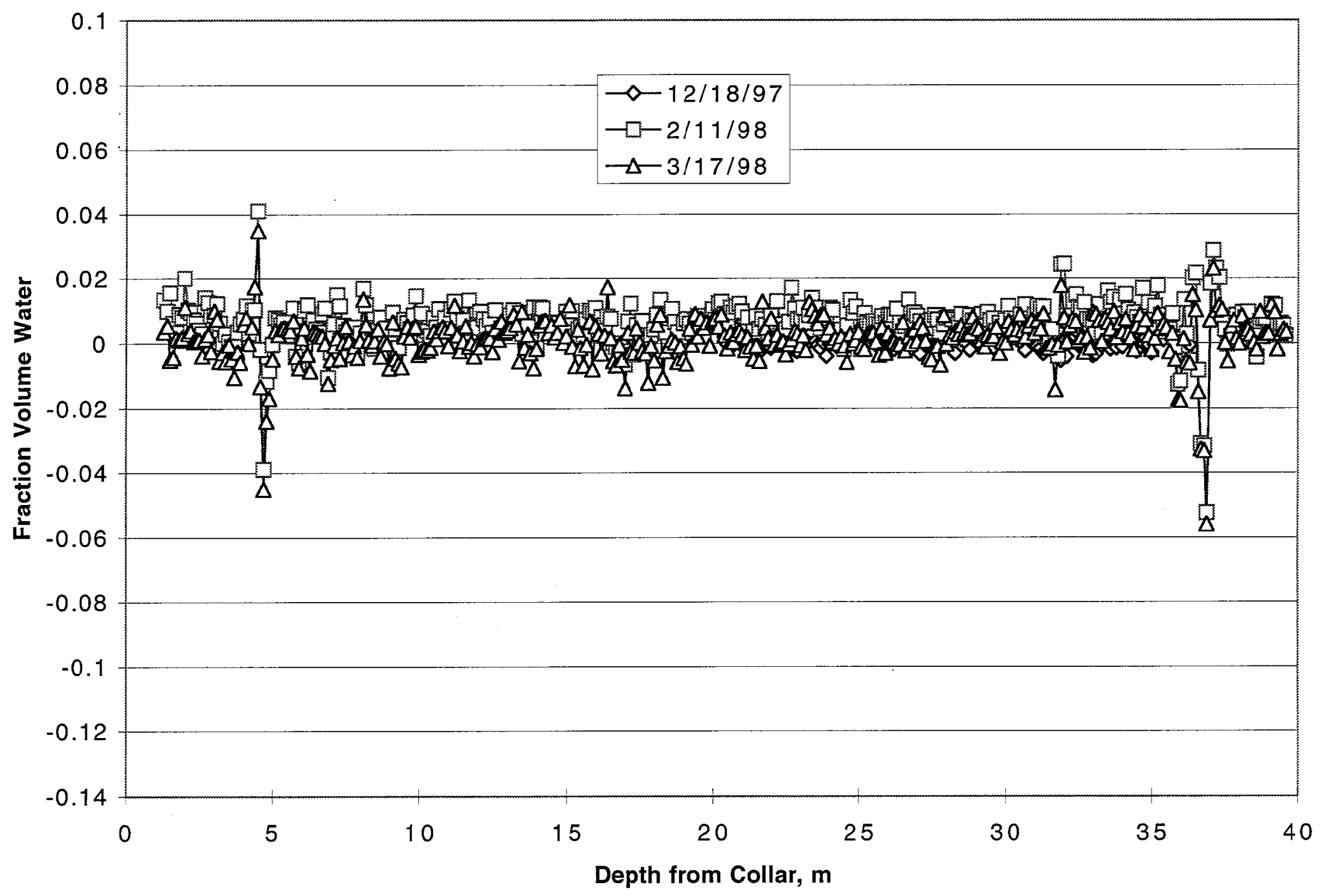

Figure 20. Difference fraction volume water content in Hole \#66 (N08). 
Difference fraction volume water content in Hole \#67 of the DST.

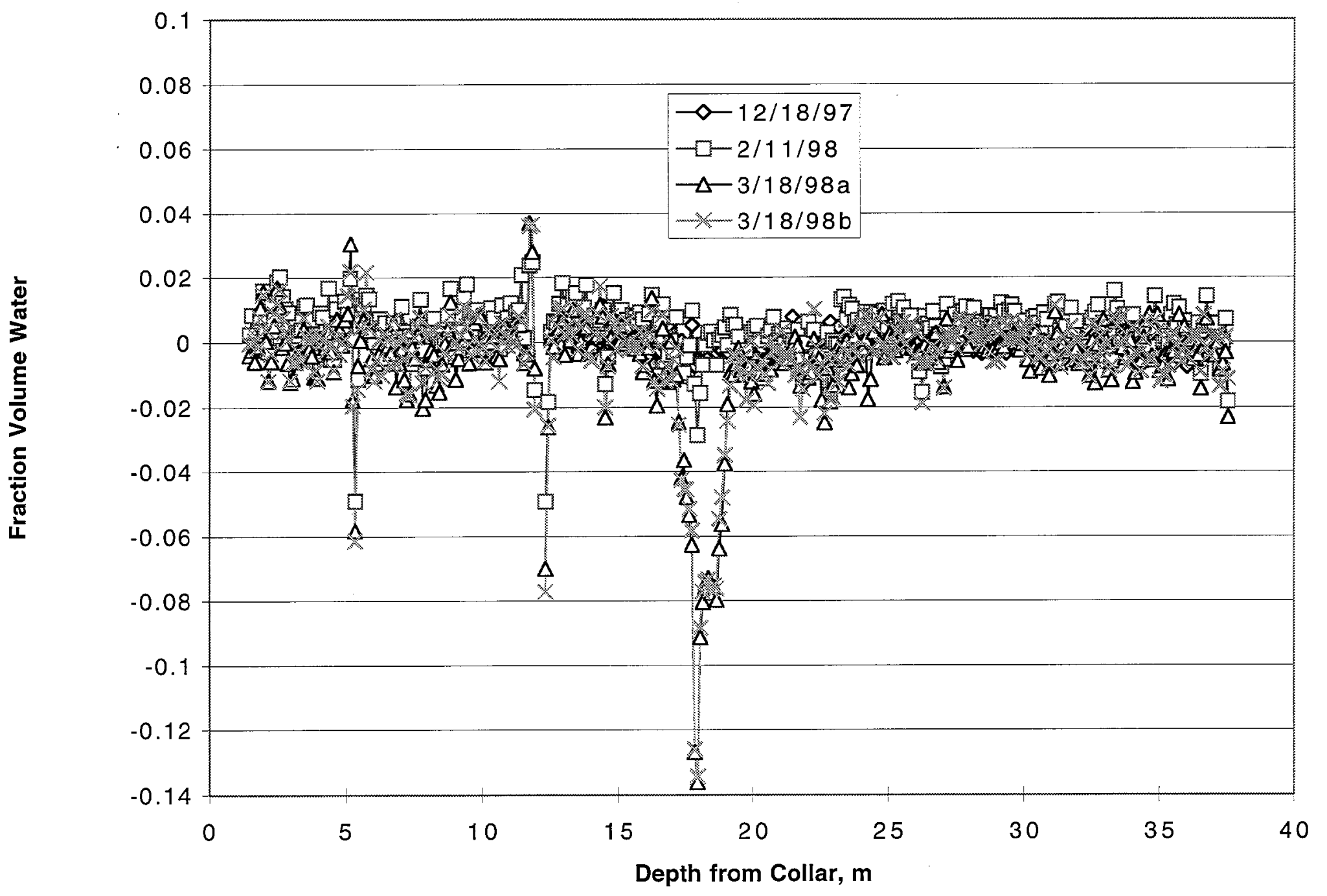

Figure 21. Difference fraction volume water content in Hole \#67 (N09). 
Difference fraction volume water content in Hole \#68 of the DST.

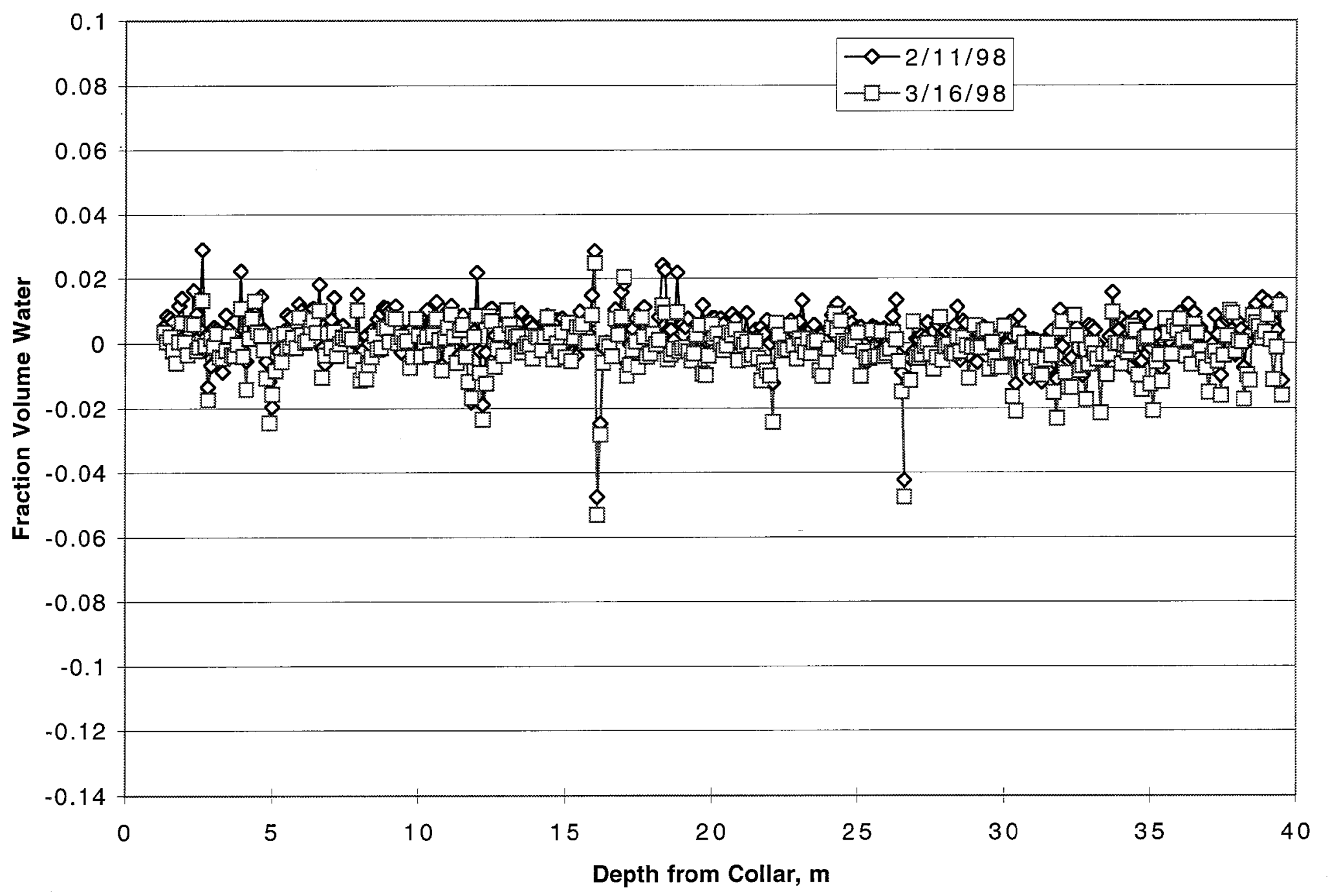

Figure 22. Difference fraction volume water content in Hole \#68 (N10). 
Difference fraction volume water content in Hole \#79 of the DST.

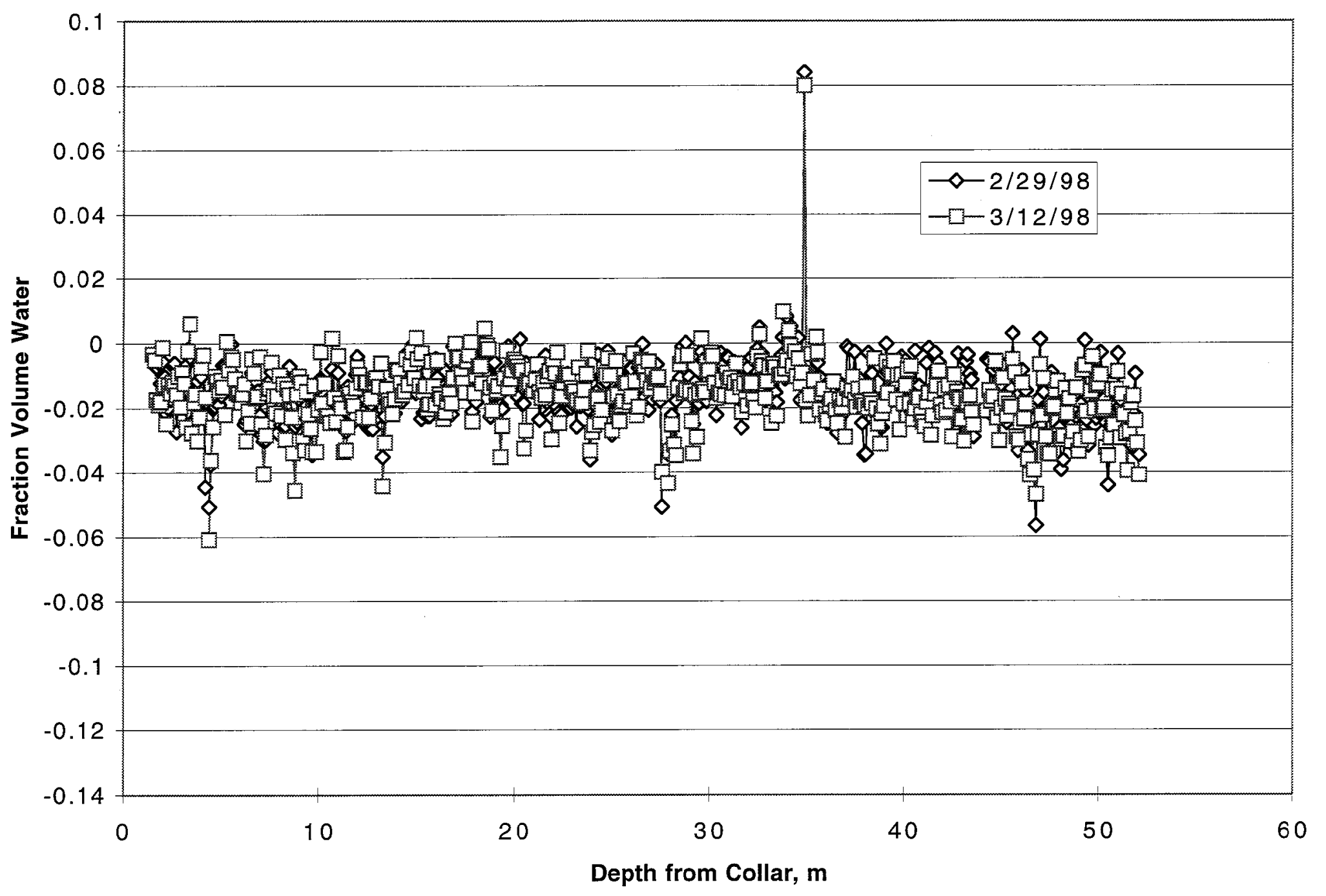

Figure 23. Difference fraction volume water content in Hole \#79 (N11). 
Difference fraction volume water content in Hole $\# 80$ of the DST.

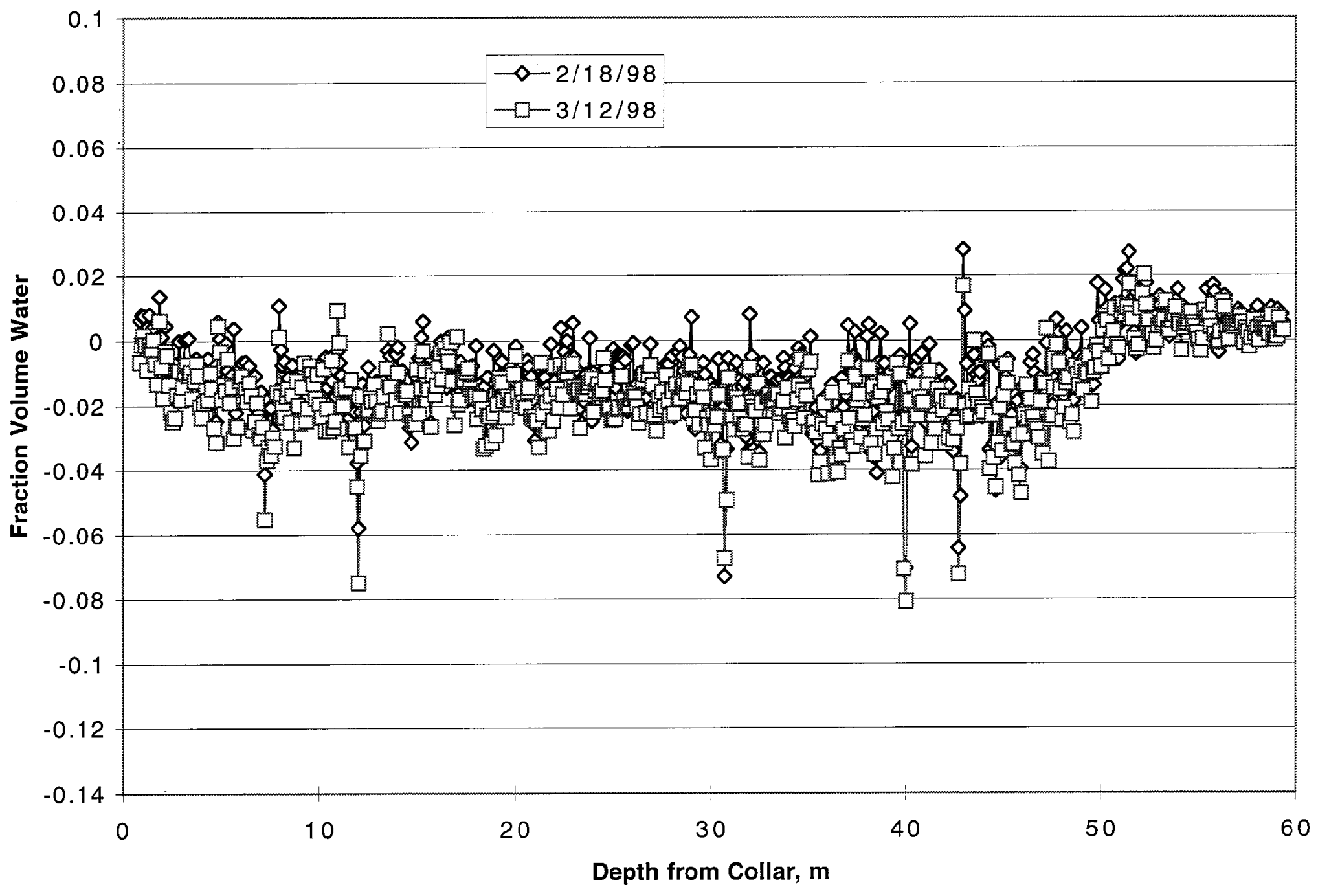

Figure 24. Difference fraction volume water content in Hole \#80 (N12). 


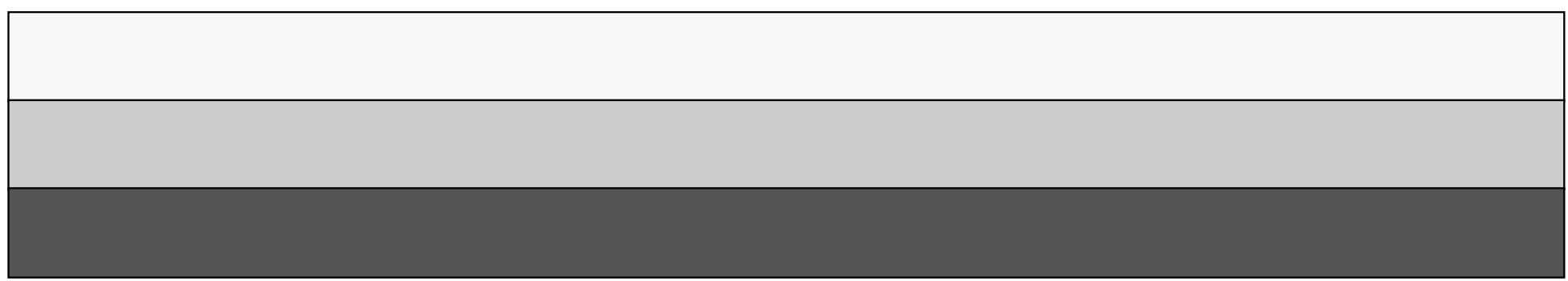

